\title{
METODOLOGIAS ATIVAS NO ENSINO DA MATEMÁTICA NO ANOS INICIAIS: APRENDIZAGEM POR MEIO DE JOGOS
}

\author{
Gesseca Camara Lubachewski \\ Universidade Regional Integrada do Alto Uruguai e das Missões, RS \\ geseca-70@hotmail.com \\ Elisabete Cerutti \\ Universidade Regional Integrada do Alto Uruguai e das Missões, RS \\ beticerutti@uri.edu.br
}

\begin{abstract}
RESUMO
O presente artigo é um estudo bibliográfico acerca das Metodologias Ativas na Matemática por meio de Jogos nos Anos Iniciais do Ensino Fundamental, voltadas para o ensino com situações que possam estimular e instigar os alunos. O objetivo do mesmo é apresentar reflexões voltadas às metodologias diferenciadas no ensino de Matemática nos Anos Iniciais e ao desenvolvimento de competências e habilidades necessárias para a compreensão da realidade, tomada de decisões fundamentadas nas mais diversas situações do cotidiano, interação entre professor-aluno e contribuições para uma aprendizagem mais significativa. $\mathrm{O}$ referencial teórico traz abordagens acerca das Metodologias Ativas no ensino da Matemática e Aprendizagem por meio de Jogos. Dentre os resultados parciais citam-se possíveis benefícios e possibilidades metodológicas para o processo de ensino-aprendizagem da Matemática, bem como a utilização de estratégias diversificadas, entre elas, a aprendizagem por meio de jogos.
\end{abstract}

Palavras-chave: Anos Iniciais. Ensino da Matemática. Metodologias Ativas.

\section{METODOLOGÍAS ACTIVAS EM LA ENSEÑANZA DE LA MATEMÁTICA EM LOS AÑOS INICIALES: APRENDIZAJE POR MEDIO DE JUEGOS}

\section{RESUMEN}

El presente artículo es un estudio bibliográfico acerca de las Metodologías Activas en las Matemáticas por medio de Juegos en los años iniciales de la Enseñanza Fundamental, orientado a una enseñanza con situaciones que puedan estimular e instigar a los alumnos. El objetivo del mismo es presentar reflexiones orientadas a las metodologías diferenciadas en la enseñanza de Matemáticas en los años iniciales y el desarrollo de competencias y habilidades necesarias para la comprensión de la realidad, toma de decisiones fundamentadas en las más diversas situaciones del cotidiano, interacción entre profesor-alumno y contribuciones para un aprendizaje más significativo. El referencial teórico trae abordajes acerca de las Metodologías Activas en la enseñanza de la Matemática y Aprendizaje a través de Juegos. Entre los resultados parciales se citan posibles beneficios y posibilidades metodológicas para el proceso de enseñanza-aprendizaje de laMatemática, así como acciones que contemplan la utilización de estrategias diversificadas, entre ellas, aprendizaje por medio de juegos.

Palabras clave: Años iniciales. Enseñanza de las Matemáticas. Metodologías Activas. 


\title{
ACTIVE METHODOLOGIES FOR MATHEMATICS TEACHING IN THE EARLY YEARS: LEARNING THROUGH GAMES
}

\begin{abstract}
This article is a bibliographical study about Active Methodologies for Mathematics through Games in the early years of Teaching School, focused on teaching situations that can stimulate and instigate students. The purpose of this study is to present reflections on differentiated methodologies in Mathematics teaching in the initial years and the development of skills and abilities needed to understand reality, making decisions based on the most diverse situations of daily life, teacher-student interaction and contributions for more meaningful learning. The theoretical framework provides approaches on Active Methodologies in the teaching of Mathematics and Learning through Games. Among the partial results are possible benefits and methodological possibilities for the teaching-learning process of Mathematics, as well as actions that contemplate the use of diversified strategies, between them, learning through games.
\end{abstract}

Keywords: Early years. Mathematics Teaching. Active Methodologies.

\section{MÉTHODOLOGIES ACTIVES DANS L'ENSEIGNEMENT DES MATHÉMATIQUES DANS LES ANNÉES INITIALES: APPRENDRE AUX JEUX}

\section{RÉSUMÉ}

Cet article est une étude bibliographique sur les méthodologies actives en mathématiques par le jeu dans les premières années de l'école élémentaire, axée sur les situations d'enseignement pouvant stimuler et stimuler les élèves. Le but de cette étude est de présenter des réflexions sur les méthodologies différenciées en enseignement des mathématiques au cours des premières années et sur le développement des compétences et des habiletés nécessaires pour comprendre la réalité, en prenant des décisions fondées sur les situations les plus diverses de la vie quotidienne, les interactions et les contributions entre enseignants et élèves. pour un apprentissage plus significatif. Le cadre théorique fournit des approches sur les méthodologies actives dans l'enseignement des mathématiques et l'apprentissage par le jeu. Parmi les résultats partiels figurent des avantages possibles et des possibilités méthodologiques pour le processus d'enseignement-apprentissage des mathématiques, ainsi que des actions qui envisagent l'utilisation de stratégies diversifiées, entre eux, apprentissage par le jeu.

Mots-clés: Premières années. Enseignement des mathématiques. Méthodologies actives.

\section{INTRODUÇÃO}

Estamos vivenciando uma complexidade em que as demandas educacionais exigem cada vez mais do profissional docente, maior articulação e interação com os fatos atuais, movimento este que envolve a formação inicial e continuada, em que os professores possam estar em constante aperfeiçoamento, pois a sociedade está cada vez mais articulada com as linhas digitais. Nestes termos, "a complexidade crescente dos diversos setores da vida no 
âmbito mundial, nacional e local tem demandado o desenvolvimento de capacidades humanas de pensar, sentir e agir de modo cada vez mais amplo e profundo, comprometido com questões do entorno em que se vive" (BERBEL, 2011, p. 25). Cabe à escola cumprir seu papel social de preparação do estudante para a sociedade e possibilitar alternativas para que haja avanços na aprendizagem dos alunos desde o início da vida escolar.

Boufleuer (2013) destaca que muitos aprendizados decorrem em razão das circunstâncias em que vivemos, pelo contexto em que estamos, pela necessidade de resolver problemas do cotidiano e, inclusive, em função dos tropeços que vamos sofrendo. Dessa maneira, a criança que nasce hoje tem condições de incorporar o legado da espécie em poucos anos. Novas práticas metodológicas na aprendizagem e no ensino permitem ao professor ensinar de maneira diferenciada e tornar as aulas atraentes, de modo a propiciar maior aprendizagem aos alunos, que cada vez mais cedo teriam contato com metodologias diferenciadas no ensino-aprendizagem.

Fadel, Bialik e Trilling, (2015) corroboram que ao analisar o atual estado dos currículos educacionais e considerar as novas demandas dos tempos atuais, fica cada vez mais claro que já passou da hora de fazer uma grande atualização em nossos objetivos do conhecimento. Melo e Sant'Ana (2012) ponderam que as metodologias de ensino e aprendizagem propõem desafios a serem superados pelos estudantes, possibilitando-os ocupar o lugar de sujeitos na construção do conhecimento, participando da análise do processo assistencial e propiciando ao professor a visão de facilitador e orientador desse processo. Neste contexto, podemos destacar a inserção das Metodologias Ativas na Matemática por meio de jogos, nos anos iniciais do Ensino Fundamental, com o propósito de alavancar o processo ensino e aprendizagem dos alunos e proporcionar aulas dinâmicas e prazerosas.

"No processo de alfabetização das crianças, a Matemática é uma aliada que coopera no processo de comunicação e no desenvolvimento de múltiplas linguagens. As crianças, desde muito pequenas, estão rodeadas de informações escritas, visuais, sonoras, artísticas, etc.”, ponderam os Cadernos de Alfabetização Matemática (2015, p. 30).

Sendo assim, as Metodologias Ativas priorizam o aluno, dando possibilidades para que o educando se envolva diretamente, participe e ponha em xeque a sua reflexão. "As Metodologias Ativas dão ênfase ao papel protagonista do aluno e todas as etapas do processo, experimentando, desenhando, criando, com orientação do professor" (BACICH; MORAN, 2018, p. 4). Ponderando, a inserção de novas práticas metodológicas nas series iniciais, na 
aprendizagem dos alunos, permite ao professor ensinar de maneira diferenciada e possibilitar avanços relevantes no processo ensino-aprendizagem dos estudantes.

\section{METODOLOGIAS ATIVAS NA MATEMÁTICA}

Sobre as Metodologias Ativas, Gewehr, Strohschoen, Marchi, Martins e Schuck (2016) corroboram que Metodologias Ativas de ensino e de aprendizagem são, de um modo geral, abordagens que os professores fazem uso para ensinar, de maneira que facilite o processo do aluno aprender.

Quando os estudantes são estimulados a realizarem estratégias para resolver problemas, formulação de hipóteses, de justificativas, a criatividade é despertada. Segundo Fadel, Bialik e Trilling (2015), o ensino para a criatividade complementa o ensino do conhecimento de conteúdo, pois pode ser a habilidade mais importante para os estudantes, pois é necessária para o desenvolvimento de soluções inovadoras para muitos desafios do século XXI. Nesta perspectiva, Libaneo (1994, p. 83) salienta que "a aprendizagem escolar é, assim, um processo de assimilação de determinados conhecimentos e modos de ação física e mental organizados e orientados no processo de ensino".

Bacich e Moran (2018) enfatizam que a aprendizagem profunda requer espaços de práticas (aprender fazendo) e de ambientes ricos em oportunidades. Sendo assim, é importante o estímulo multissensorial e a valorização dos conhecimentos prévios dos estudantes para alavancar os novos conhecimentos. A aprendizagem se constrói através de processos múltiplos, com a inserção de Metodologias Ativas, processos formais, informais, técnicos, organizados, abertos e com intencionalidade pedagógica.

Diferentes possibilidades metodológicas em consonância com as Metodologias Ativas na Matemática nas turmas iniciais do Ensino Fundamental, servem como ferramenta no planejamento e na aplicação das aulas.

Sabe-se que a típica aula de Matemática a nível de primeiro, segundo ou terceiro graus ainda é uma aula expositiva, em que o professor passa para o quadro negro aquilo que ele julgar importante. O aluno, por sua vez, copia da lousa para o seu caderno e em seguida procura fazer exercícios de aplicação, que nada mais são do que uma repetição na aplicação de um modelo de solução apresentado pelo professor. (D’AMBR'OSIO, 1989, p. 15). 
A utilização de ambiente de aprendizagem dinâmico permite ao professor trabalhar de maneira diferenciada e propicia aos alunos a assimilação de modo mais fácil do conteúdo, além de possibilitar um aprendizado mais significativo.

Bacich e Moran (2018) salientam que:

Metodologias Ativas são estratégias de ensino centradas na participação efetiva dos estudantes na construção do processo de aprendizagem, de forma flexível, interligada e hibrida. As metodologias ativas, num mundo conectado e digital, expressam por meio de modelos híbridos, com muitas combinações. A junção de metodologias ativas com modelos flexíveis e híbridos traz contribuições importantes para o desenho de soluções atuais para os aprendizes de hoje. (BACICH; MORAN, 2018, p. 4).

As Metodologias Ativas possuem como princípio priorizar o aluno, possibilitando que o educando se envolva diretamente, participe e ponha em xeque a sua reflexão. Bacich e Moran (2018, p. 4) salientam que "as Metodologias Ativas dão ênfase ao papel protagonista do aluno e todas as etapas do processo, experimentando, desenhando, criando, com orientação do professor".

Prestes (2003) salienta que o ensino de Matemática para os anos iniciais que, nos currículos dos cursos de formação, é abordado na disciplina de Metodologia de Ensino, restrita muitas vezes a instrumentalização do professor.

Logo, trazer para a sala de aula, além dos conteúdos, metodologias atrativas e interativas, de maneira a aprimorar e envolver os alunos na aprendizagem. No entanto, nem todos os conteúdos o professor proporcionará uma metodologia diferenciada de Ensino, mas é importante o docente utilizar na maioria das aulas novas práticas de ensino.

"Boas experiências com a Matemática logo no início da alfabetização poderão ser importantes para que os alunos desenvolvam a confiança e o prazer em aprender Matemática", corroboram os Cadernos de Alfabetização Matemática (2015, p. 62).

Portanto, propiciar ao aluno ensino-aprendizagem significativa através da inserção das Metodologias Ativas é relevante, tendo em vista que no mundo estão acontecendo transformações, que exigem uma ênfase em certos tópicos, principalmente os relacionados ao ensino para os estudantes.

As Metodologias Ativas trazem relevantes contribuições para o ensino do aluno e, também para a escola, a partir dos quais os discentes poderão ser autônomos, confiantes, capazes de resolver problemas, profissionais qualificados, atualizados e protagonistas do seu aprendizado, bem como, tornando-os participativos, dinâmicos e criativos sob o 
acompanhamento do professor com enfoque na investigação, descoberta ou até mesmo, resolução de problemas, tendo em vista que um ensino menos centralizado no professor já perpassa vários anos, conforme elucidava Dewey (1944).

Segundo Bacich e Moran (2018), a Educação baseada no processo ativo de busca do conhecimento do estudante, deveria exercer sua liberdade, formar cidadãos competentes, criativos, com uma proposta de aprendizagem pela ação. O uso das Metodologias Ativas está ancorado no pressuposto que o estudante assuma o protagonismo pedagógico, is to é, seja sujeito do aprender e fazem provocações aos alunos antes mesmo da própria aula, possibilitando uma aprendizagem ativa. Para Bacich e Moran (2018, p. 10):

Metodologias ativas apontam a possibilidade de transformar aulas em experiências de aprendizagem mais vivas e significativas para os estudantes da cultura digital, cuja expectativas em relação ao ensino, a aprendizagem a ao próprio desenvolvimento e formação são diferentes do que expressavam as gerações anteriores.

Evidenciamos que as práticas pedagógicas na Educação Básica buscam valorizar os estudantes, bem como colocá-los protagonistas da aprendizagem, apresentando alternativas para que o processo de ensino-aprendizagem dos mesmos torne-se significativo, em no seu ritmo e seu tempo. Moran, Maseto e Behrens (2013, p. 91), enfatizam que:

A pratica pedagógica do professor precisa desafiar os alunos a buscarem uma formação humana, crítica e competente, alicerçada numa visão holística, com uma abordagem progressista num ensino com pesquisa que levará o aluno a aprender. $\mathrm{O}$ aprendizado deve ser impulsionado pela curiosidade, pelo interesse, pela crise, pela problematização e pela busca de soluções possíveis para aquele momento histórico com visão de que não são respostas únicas, absolutas e inquestionáveis.

Assim, na prática pedagógica o professor pode propor atividades, nas quais oportunizam os alunos a investigar, e ultrapassar barreiras, na qual o aluno torna-se produtor do conhecimento. Uma estratégia de uso de Metodologias Ativas parte dos professores, que pode trabalhar suas aulas de maneira a auxiliar seus alunos, simultaneamente, sempre procurando que os educandos possam construir seus próprios conhecimentos, mostrando a eles as aplicabilidades e habilidades dos conteúdos estudados.

As pesquisas na área de psicologia mostram que o engajamento ativo em experiências de aprendizagem geralmente traz melhores resultados no aprendizado. Em vez de apenas ouvir, ler e fazer exercícios habituais, os estudantes praticam suas habilidades de pensamento de alto nível 
investigando, debatendo, averiguando diferentes pontos de vista, etc. Combinada ao aprendizado ativo, a abordagem construtiva ao aprendizado enfatiza e promove os aspectos sociais (caráter) do aprendizado (o conhecimento é muitas vezes construído socialmente) e o aspecto de habilidades criativas (o conhecimento é aprendido ao criá-lo ou recriá-lo). (FADEL; BIALIK; TRILLING, 2015, p. 104).

Dentre as Metodologias Ativas, está inserida a Aprendizagem por Meio de Jogos, possibilidade de ensino relevante para ampliar a aprendizagem dos estudantes dos anos iniciais envolvendo a Matemática e servindo de motivação para o professor criar situações de integração.

\section{APRENDIZAGEM POR MEIO DE JOGOS}

Dentre as alternativas das Metodologias Ativas, destacamos também a Aprendizagem por meio de jogos. A inserção de jogos nas aulas de Matemática proporciona ao aluno indagações e resgate de conceitos matemáticos do nível da ação para uma posterior compreensão e sistematização.

O professor é o mediador do aluno na atividade de utilização de jogos. Bacich e Moran (2018) destacam que os jogos em sala de aula podem ser utilizados como um instrumento motivacional para as aulas, e para uma aprendizagem mais rápida e próxima da vida real, uma vez que auxiliam no desenvolvimento de habilidades como as de observações, análise, tomada de decisões e argumentação, bem como motivam os alunos a buscar compreender melhor os propósitos dos conteúdos matemáticos.

Os Parâmetros Curriculares Nacionais referentes à área destacam que "os jogos podem contribuir para um trabalho de formação de atitudes - enfrentar desafios, lançar-se a busca de soluções, desenvolvimento da crítica, criação de estratégias e da possibilidade de alterá-las quando o resultado não é satisfatório - necessárias para aprendizagem matemática" (PCNs, 1997 apud GRANDO, 2004, p. 14).

A inserção da Aprendizagem por meio de Jogos nas Metodologias Ativas possibilita aos estudantes da Educação Básica (anos iniciais) adquirirem uma compreensão eficaz da disciplina de Matemática e uma visão ampliada de conhecimento matemático, além de gerar novos procedimentos para a educação, superar métodos antigos e faz com que o professor possua mais um modelo metodológico através das Metodologias Ativas. 
As atividades de jogos permitem ao professor analisar e avaliar os seguintes aspectos: -compreensão: facilidade para entender o processo do jogo assim como o autocontrole e o respeito a si próprio; - facilidade: possibilidade de construir uma estratégia vencedora; -possibilidade de descrição: capacidade de comunicar o procedimento seguido e da maneira de atuar; - estratégia utilizada: capacidade de comparar com as previsões ou hipóteses. (PCNs, 1998, p. 46).

Assim, os jogos são recursos relevantes que podem contribuir para mudanças significativas no ensino da Matemática, através de seu modo atrativo e criativo. Dessa maneira, o jogo, em seus vários aspectos, pode desempenhar uma função impulsionadora do processo de desenvolvimento e aprendizagem da criança, afirmam Alves e Bianchin (2010).

Piaget (1998) acredita que o jogo é essencial na vida da criança, pois diante do jogo, a criança repete uma determinada situação por prazer, por ter apreciado seus efeitos e em torno dos 2-3 e 5-6 anos percebe-se a ocorrência dos jogos simbólicos, que satisfazem a necessidade da criança de não somente relembrar o mentalmente o acontecido, mas de executar a representação.

Para crianças pequenas, os jogos são as ações que elas repetem sistematicamente mas que possuem um sentido funcional (jogos de exercício), isto é, são fonte de significados e, portanto, possibilitam compreensão, geram satisfação, formam hábitos que se estruturam num sistema. Essa repetição funcional também deve estar presente na atividade escolar, pois é importante no sentido de ajudar a criança a perceber regularidades. (PCNs, 1997, p. 88).

Alves e Bianchin (2010, p. 284) corroboram que o "lúdico, manifestam-se suas potencialidades e, ao observá-las, poderemos enriquecer sua aprendizagem, fornecendo por meio dos jogos os "nutrientes" do seu desenvolvimento".

A aprendizagem através dos jogos pode ser por meio dos jogos convencionais (tabuleiros, jogos de tabuada, bingos matemáticos, jogos construídos manualmente) e jogos digitais com acesso online, os quais ambos, estão inseridos no processo de ensino e aprendizagem baseados nas Metodologias Ativas. Nesse âmbito, "os alunos podem formular questões e planejar linhas de investigação de forma diversificada. Eles podem participar do processo de investigação, salientam Alro e Skovmose (2006, p. 55)

Para acesso online, encontram-se disponíveis sites educacionais que demandam jogos que oportunizam a interação do aluno e contribuem para o desenvolvimento de aspectos cognitivos por meio do acesso tecnológico. 
A ideia fundamental é a melhor utilização das tecnologias na sala de aula, articulando com estratégia e criatividade, visando à qualidade do produto final que é o aprendizado. Partimos do princípio de que toda a atividade, usando os artefatos tecnológicos, possui significado de operacionalidade para o aluno, o que proporciona interatividade e supera a visão do aluno receptor. É necessário que os docentes tenham em mente que a tecnologia é um alicerce, é um meio. (SCHEID; KONFLANZ; CERUTTI, 2017, p. 32).

Sobre ensino e aprendizagem através de jogos tecnológicos, podemos considerar o aluno participativo, ativo e sujeito do aprendizado. Os jogos através das tecnologias trazem motivação e transformação significativas para aprendizagem dos estudantes, diante desta reflexão, não há obrigatoriedade do professor utilizar estes métodos, apenas são possibilidades de ensino, nas aulas de Matemática. "Todo material é fonte de informação, mas nenhum deve ser utilizado com exclusividade. É importante haver diversidade de materiais para que os conteúdos possam ser tratados da maneira mais ampla possível", corroboram os Parâmetros Curriculares Nacionais (1997, p. 67).

Para Barbosa e Moura (2013) a metodologia de ensino é o elemento muito importante, ou seja, essencial do currículo de formação, pois é a chave da formação. Neste contexto, todos os recursos e métodos de ensino são importantes ao estarem agregados ao aprendizado dos alunos. Para Tardif (2013, p. 118), "o ensino é uma atividade humana, um trabalho interativo, ou seja, um trabalho baseado em interações".

\section{CONSIDERAÇÕES FINAIS}

Considera-se a relevância da Matemática no cotidiano. É importante o estudo dessa área ser instigante, porém desafiador. Trabalhar com esta disciplina é proporcionar ao aluno possibilidades de resolver situações problemas e inserir novas possibilidades metodológicas no ensino das Matemática.

Assim, Metodologias Ativas inseridas no ensino-aprendizagem dos estudantes, englobando também os anos iniciais são estratégias e mecanismos para interação professoraluno e para que desde cedo alunos tenham contato com diversas possibilidades de ensino matemático.

É relevante alunos com dificuldades de aprendizagem terem contato com materiais concretos, a exemplo da Metodologias Ativas por meio de Jogos, dessa maneira proporciona ao educando a manipulação deste material, tornando um aprendizado mais significativo. 
Destacamos o lúdico e os jogos em sala de aula como possibilidades aos estudantes da escola básica de obterem uma compreensão e um conhecimento eficaz de problemas matemáticos. A busca de novos procedimentos para a educação, além de superar métodos antigos, faz com que o professor tenha novas formas de trabalhar.

Metodologias Ativas voltadas à Educação Matemática nos anos iniciais do Ensino Fundamental, é caminho para elaboração de propostas e metodologias diferenciadas de ensino que devem então se reverter em aprendizagens significativas.

Assim sendo, Metodologias Ativas por meio de jogos inseridas aos alunos no início da vida escolar, podem de alguma maneira contribuir para um trabalho de formação de atitudes, de resolução de desafios, e a utilização de atividades diversificadas em aulas de Matemática desencadeia um aspecto afetivo entre aluno e professor.

\section{REFERÊNCIAS}

ALRO, H.; SKOVSMOSE, O. Diálogo e aprendizagem em educação matemática. Belo Horizonte Autêntica,2006

ALVES, Luciana; BIANCHIN, Maysa Alahmar. O jogo como recurso de aprendizagem. Revista Psicopedagogia [Online], v. 27, n. 83, p. 282-287, 2010

BARBOSA, Eduardo Fernandes; MOURA, G. Dácio. Metodologias Ativas de Aprendizagem na Educação profissional e Tecnológica. Tec. SENAC, Rio de Janeiro, v. 39, n. 2, p. 48-67, maio/ago. 2013.

BERBEL N. Neusi Aparecida. As metodologias ativas e a promoção da autonomia de estudantes.2011Disponível em:

http://www.uel.br/revistas/uel/index.php/seminasoc/article/view/10326.pdf. Acesso em: 07 maio 2018.

BOUFLEUER, José Pedro. A aprendizagem em situação pedagógica e na mediação da docência. In: FONTELLA, A. S.; SAUSEN, I.T.; ALLEBRANDT, L. I. O curso de pedagogia da Unijuí - 55 anos. Ijuí, Ed. Unijuí, 2013. p. 103-121.

BRASIL. Secretaria de Educação Fundamental. Parâmetros Curriculares Nacionais: Matemática. Brasília: MEC/SEF. 1997

BRASIL. Secretaria de Educação Básica. Pacto Nacional pela Alfabetização na Idade Certa. Brasília: MEC, 2015

BRASIL. Secretaria de Educação Fundamental. Parâmetros curriculares nacionais: introdução aos parâmetros curriculares nacionais. Brasília: MEC/SEF, 1997. 126p. 
CERUTTI, Elisabete; PORTO, Ana Paula Teixeira. Possibilidades didáticas através de site infantil para os anos iniciais do Ensino Fundamental. Revista Ciências Humanas, Frederico Westphalen, RS v. 18 n.2 [31] set./dez. 2017

D’AMBROSIO, Beatriz S. Como ensinar matemática hoje? Temas e Debates, SBEM, Brasília, ano II, n. 2, p. 15-19, 1989.

D'AMBRÓSIO, Ubiratan. Educação Matemática: da teoria à prática. 4. ed. Campinas-SP: Papirus, 1998.

FADEL, Charles; BIALIK, Maya; TRILLING, Bernie. Educação em quatro dimensões: as competências que os estudantes precisam para atingir o sucesso. Traduzido por Instituto Península e Instituto Ayrton Senna, 2015.

GEWEHR, Diógenes; STROHSCHOEN, G. A. Andreia; MARCHI, I. Miriam; MARTINS, N. Silvana; SCHUCK, J. Rogério. Metodologias Ativas de ensino e de aprendizagem: uma abordagem de iniciação à pesquisa. Revista Ensino \& Pesquisa, v. 14, n. 01, p. 225-246, jan./jun. 2016.

GRANDO, Célia Regina. O jogo e a Matemática no contexto da sala de aula. São Paulo: Paulus, 2004.

LIBANÊO, José Carlos. Didática. São Paulo: Cortez, 1994.

MELO, C. Bárbara de; SANT’ANA, Geisa. A prática da Metodologia Ativa: compreensão dos discentes enquanto autores do processo ensino-aprendizagem. Revista Ciências Saúde, p. 327-339, 2012. Disponível em: http://pesquisa.bvsalud.org/bvsecuador/resource/pt/mis36480?lang=pt. Acesso em: 05 maio 2018.

PIAGET, J. A psicologia da criança. Rio de Janeiro: Bertrand Brasil, 1998.

PRESTES, L. M.. A formação matemática docente para os Anos Iniciais do Ensino Fundamental: desafios e perspectivas. Revista de Ciências Humanas (Frederico Westphalen), URI - Frederico Westphalen, v. 1, n.5, p. 71-89, 2004

SCHEID, Neusa Maria John; KONFLANZ, Tais Lazzari; CERUTTI, Elisabete. Contribuições das tecnologias da informação e da comunicação em metodologias alternativas para o uso de animais não-humanos em aulas experimentais de ciências biológicas. In: NOGUEIRA, Fernanda; FERREIRA, Arnaldo Telles (Orgs.). Comunicação Educação e tecnologia: mídias e cultura digital no ideário coletivo. Campinas, SP: Librum Editora, 2017. $216 \mathrm{p}$

Recebido em: 29 de junho de 2019

Aceito em: 08 de outubro de 2019 